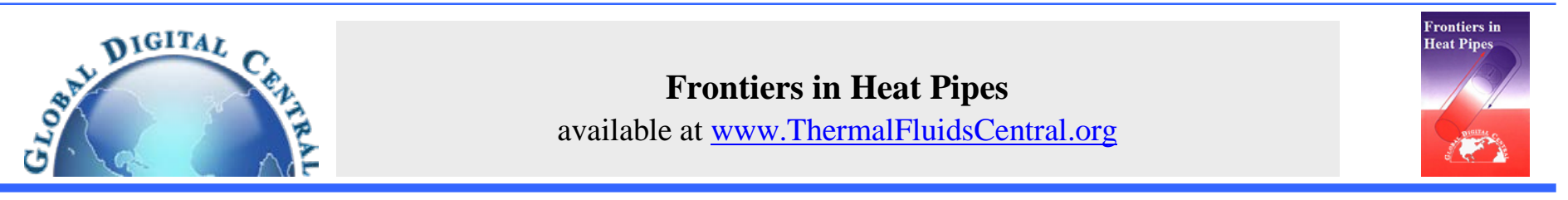

\title{
PERFORMANCE OF TWO PHASE GRAVITY ASSISTED THERMOSYPHON USING NANOFLUIDS
}

\author{
R. Shanthi ${ }^{\mathrm{a}, *}$, R. Velraj ${ }^{\mathrm{b}}$ \\ ${ }^{a}$ Rajalakshmi Engineering College, Chennai, Tamilnadu, 602 105, India \\ ${ }^{b}$ Institute for Energy Studies, Anna University, Chennai, Tamilnadu, 600 025, India
}

\begin{abstract}
The recent pioneering advancement in the use of nanofluids as the working fluid in the two phase gravity assisted thermosyphon (TPGAT) significantly improved the heat transfer performance. In the present study, the performance enhancement of TPGAT using carbonaceous and metal based nanofluid as the working fluid is investigated. The experiment are conducted at various heat input in the evaporator and at different fill ratios. The results of the experiments revealed that the nanoparticles play a major role in enhancing the performance by bombarding the formation of vapour bubbles in the evaporator section. It is also found that the fill ratio has varying role in the condenser and evaporator section at various heat input of the evaporator section.
\end{abstract}

Keywords: Nanoparticles, nanocrystals, fill ratio, carbon, Alumina

\section{INTRODUCTION}

The two phase gravity assisted closed thermosyphon (TPGAT) are highly efficient heat transfer devices which operate by re-circulating a fluid within a closed hollow tube. This device makes use of high heat transfer coefficients available during phase change of the working fluid and this facilitates a larger amount of heat transfer in a compact device. The pioneering advancement in the use of nanofluid as the heat transfer fluid significantly improved the heat transfer performance in such systems. Recently Shanthi et al. (2012) presented a review on a various unique features as preparation of nanofluids, conduction, convection heat transfer enhancement with nanofluids, pool boiling in nanofluids and its application in various fields of engineering.

Maxwell (1873) initiated a novel concept of dispersing solid particles in base fluids to break the fundamental limit of heat transfer fluids having low thermal conductivities. Most of these earlier studies on this concept used millimeter or micrometer solid particles, which led to major problems such as rapid settling of the solid spherical particles in the fluids, clogging in micro channels and surface abrasion. In addition, the high pressure drop caused by these particles limited their practical applications. The current and envisioned applications in such miniaturized devices call for special fluids to remove the heat as efficiently as possible. The miniaturization trend and modern nanotechnology provided an opportunity to process and produce particles with average crystallite sizes below $50 \mathrm{~nm}$. Choi (1995) conceived the novel concept of nanofluids by making use of these particle sizes in the order of 1 to $100 \mathrm{~nm}$. Choi and Eastman (1995) coined the term nanofluids. Nanofluids belong to a class of nanotechnology based heat transfer fluids produced by dispersing nanometer-sized particles in conventional heat transfer fluids along with a surfactant to increase their thermal stability. Compared with suspended conventional particles of milli or micro meter dimensions, nanofluids show better stability, high thermal conductivity with negligible pressure drop (Wang and Mujumdar, 2007). By suspending nano sized particles in heating or cooling fluids, the heat transfer performance of such fluids can be significantly improved.
Bang and Chang (2005) observed a 200\% increase in critical heat flux (CHF) on the measured pool boiling curves of $\mathrm{Al}_{2} \mathrm{O}_{3}$ water nanofluids. Naphon et al. (2009) also have used nanofluid as working fluid in a heat pipe and stated that at optimum condition for pure refrigerant, the heat pipe with $0.1 \%$ concentration of nanoparticles operates with efficiency higher than that with pure refrigerant. Kang et al. (2006) measured the temperature distribution and thermal resistance of a conventional grooved circular heat pipe with water based nanofluids containing 1 to $50 \mathrm{ppm}$ of $35 \mathrm{~nm}$ silver nanoparticles. The result shows that at the same charge volume, the thermal resistance of the heat pipe with nanofluids is reduced by $10 \%$ to $80 \%$ compared with that of DI water at an input power of 30 to 60 W. The results are compared with those of Wei et al. (2005). They showed that the maximum reduction in the thermal resistance of the heat pipe is $50 \%$ for $10 \mathrm{~nm}$ silver nanoparticles and $80 \%$ for $35 \mathrm{~nm}$ silver nanoparticles

An experimental study was carried out by Liu et al. (2010) to understand the heat transfer performance of a miniature thermosyphon using water-based carbon nanotube (CNT) suspensions as the working fluid. Effects of the CNT mass concentration and the operation pressure on the average evaporation and condensation heat transfer coefficients, the critical heat flux and the total heat resistance of the thermosyphon were investigated and discussed. Experimental results show that CNT suspensions can apparently improve the thermal performance of the thermosyphon and there is an optimal CNT mass concentration (about 2.0\%) to achieve the maximum heat transfer enhancement. Noie et al. (2009) suspended $\mathrm{Al}_{2} \mathrm{O}_{3}$ nanoparticles in various volume concentration of 1 $3 \%$ and used in a two phase closed thermosyphon as working media. Experimental results showed that for different input powers, the efficiency of the two phase closed thermosyphon increases up to $14.7 \%$ when $\mathrm{Al}_{2} \mathrm{O}_{3}$ /water nanofluid was used instead of pure water. Temperature distributions on two phase closed thermosyphon confirm these results too.

Paramatthanuwat (2010) studied the heat transfer characteristics of a two-phase closed thermosyphon at normal operating condition. The thermosyphon was made by copper tube with 7.5, 11.1 and 
$25.4 \mathrm{~mm}$ ID. The experiments were conducted for different filling ratios of 30, 50 and $80 \%$ by evaporator length and aspect ratios of 5 , 10 , and 20 in vertical position. Pure water and de ionized water (DI) mixed with silver nanofluid were used as working fluids and compared. The working temperatures were 40,50 and $60^{\circ} \mathrm{C}$. It was found that, the maximum heat transfer rate of $750.81 \mathrm{~W}$, was achieved for aspect ratio of 20 (internal diameter of $25.4 \mathrm{~mm}$ ) and working temperature of $60^{\circ} \mathrm{C}$. The heat transfer rate for DI water mixed silver nanofluids is approximately $70 \%$ high when compared with pure water. Huminic et al. (2011) studied the effects of two phase closed thermosyphon for various inclination angle, operating temperature and nanoparticles concentration levels on the heat transfer characteristics of two phase closed thermosyphon. An experimental study was carried out by Manimaran et al. (2012) to investigate the thermal characteristics of heat pipe using nanofluid and Deionized water (DI water). The experimental results indicated that the thermal efficiency increases when nanoparticles were added with the DI water and also the heat pipe which uses nanofluid as working fluid shows lower thermal resistance value when compared to the heat pipe which uses DI water alone.

It is construed from the present literature survey that the nanoparticles have a significant effect on the enhancement of heat transfer characteristics of two phase closed thermosyphon. Hence in the present study, $\mathrm{Al}_{2} \mathrm{O}_{3} /$ water, vegetable base carbon nano crystal particle (VBCNCP)/water and animal base carbon nano crystal particle (ABCNCP)/water are employed as working medium in the conventional TPGAT to investigate the efficiency improvement of TPGAT. The heat transfer characteristics of TPGAT with various nanofluids of different nanoparticle concentrations are compared with that of the base fluid at various evaporator heat inputs and fill ratios.

\section{PREPARATION OF NANOFLUIDS}

In the present work, a two-step method was used to produce uniform and stable nanofluids by adding $\mathrm{Al}_{2} \mathrm{O}_{3}$ with an average particle diameter of $40 \mathrm{~nm}$ and a density of $3900 \mathrm{~kg} / \mathrm{m}^{3}$ to distilled water. The method of preparation of nanofluids include the following process. A weighed known quantity of alumina nanoparticles is mixed with distilled water and the $\mathrm{Al}_{2} \mathrm{O}_{3}$ - water mixture is agitated well. The mixture is sonicated with an ultrasonic probe for a duration of one hour to produce uniform dispersion of nanoparticles in the distilled water. No precipitation or settlement of nanoparticles was observed after $24 \mathrm{~h}$ of settling the suspension. The alumina nanofluids were made in different volume fractions $(0.5 \%, 1 \%$ and $2 \%)$ and no surfactants were used as they may have influence on the thermo physical properties and as they have no considerable effect on boiling process (Wasekar et al, 2000). The similar process was followed for preparing VBCNCP-water and ABCNCP-water nanofluids. The VBCNCP and ABCNCP synthesized by Venkatnarayanan et al. (2011) were used for the preparation of nanofluids. The particle size of VBCNCP varies from $8 \mathrm{~nm}$ to $58 \mathrm{~nm}$, while for ABCNCP it varies from $18 \mathrm{~nm}$ to $48 \mathrm{~nm}$. The scanning electron microscope images of VBCNCP and ABCNCP are shown in Fig. 1. The vegetable base and animal base carbon nanofluids were also prepared in different volume fractions $(0.5 \%$ and $1 \%)$

\section{EXPERIMENTAL SET-UP AND PROCEDURE}

The schematic of the experimental set-up and the TPGAT test section are shown in fig. 2 and fig. 3 respectively. TPGAT is made of copper tube with internal diameter $12.5 \mathrm{~mm}$ and $1 \mathrm{~mm}$ thickness and 300 $\mathrm{mm}$ long. The evaporator and condenser sections had $75 \mathrm{~mm}$ and 200 $\mathrm{mm}$ length respectively. Heat is supplied to the evaporator section by a Nichrome heating coil of heating capacity $1000 \mathrm{~W}$ wound around the entire section. The outer portion of the electrical heater is insulated to prevent heat loss. A variac is connected to the heating element to vary the heat input given to the evaporator section. The condenser is placed inside the water cooled jacket. The inlet and outlet of the jacket is designed in such a manner that a counter flow condition for the vapour flow exists over the entire length of the section. Five thermocouples (Sheath protected, K-type) are used to measure the temperature at axial locations on the thermosyphon tube. Two thermocouples (Sheath protected, K-type) are used to measure the temperature of the fluid at inlet and outlet of the cooling jacket. The thermocouples are connected to a PC based data acquisition system to record the temperature. The thermosyphon is cleaned with solid particles, oils and oxides prior to all experiments. This involves the following three procedure, cleaning with trichloroethane and methanol followed by vacuum drying. Cleaning is essential whenever there is a change in the working fluid.
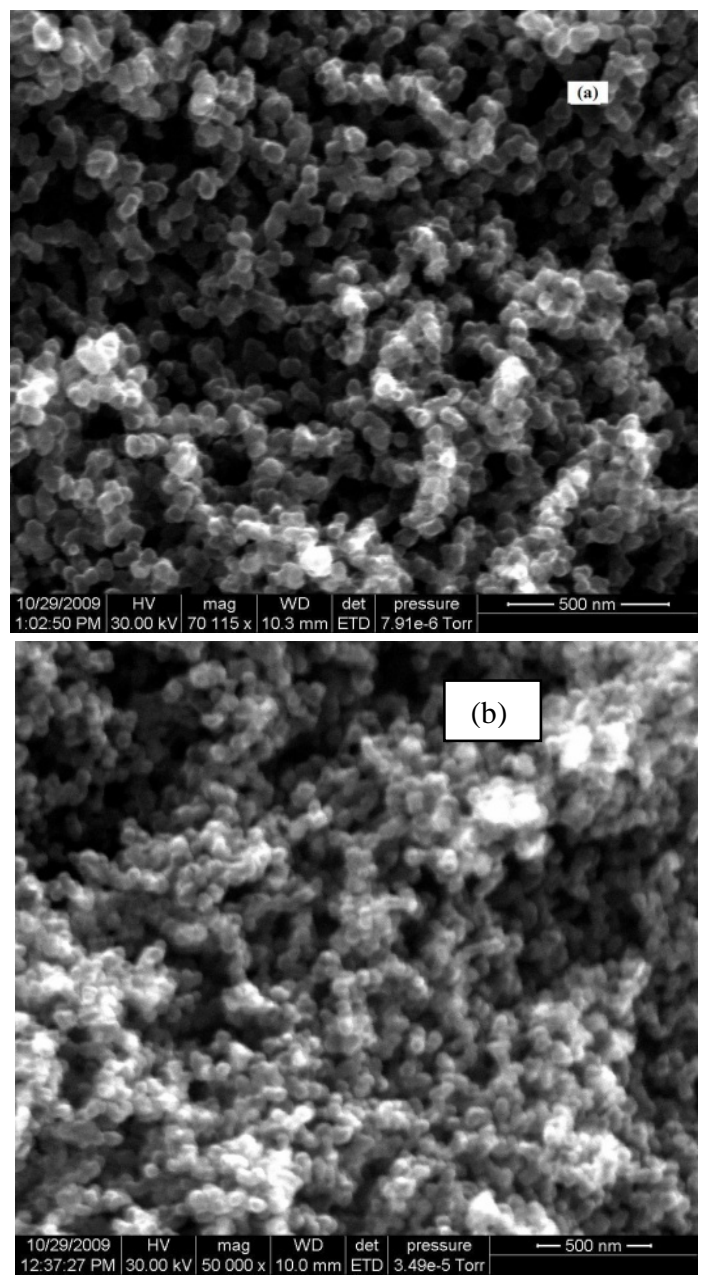

Fig. 1 SEM images (a) VBCNCP (b) ABCNCP

The experiments were conducted in TPGAT for various fill ratios of $100 \%, 75 \%$ and $50 \%$. At each fill ratio experiments were repeated at various heat input of $115 \mathrm{~W}, 160 \mathrm{~W}, 200 \mathrm{~W}$ and $230 \mathrm{~W}$ by varying the voltage and current. The mass flow rate of water flowing through the condensor section is measured using the rotameter. The experiments showed that 35 min was needed for the system to reach steady state condition which was also expressed by Park et al. (2002). After the system attained the steady state, the temperature of the working fluid at various axial locations and the temperatures of water entering and leaving the condensor section are measured. Before proceeding the experiment with nanofluid, baseline experiments were conducted with pure water. Once the repeatability of the baseline was established, water based nanofluids were used as the working fluid. Experiments are conducted for all the nanofluids prepared with various concentrations. 


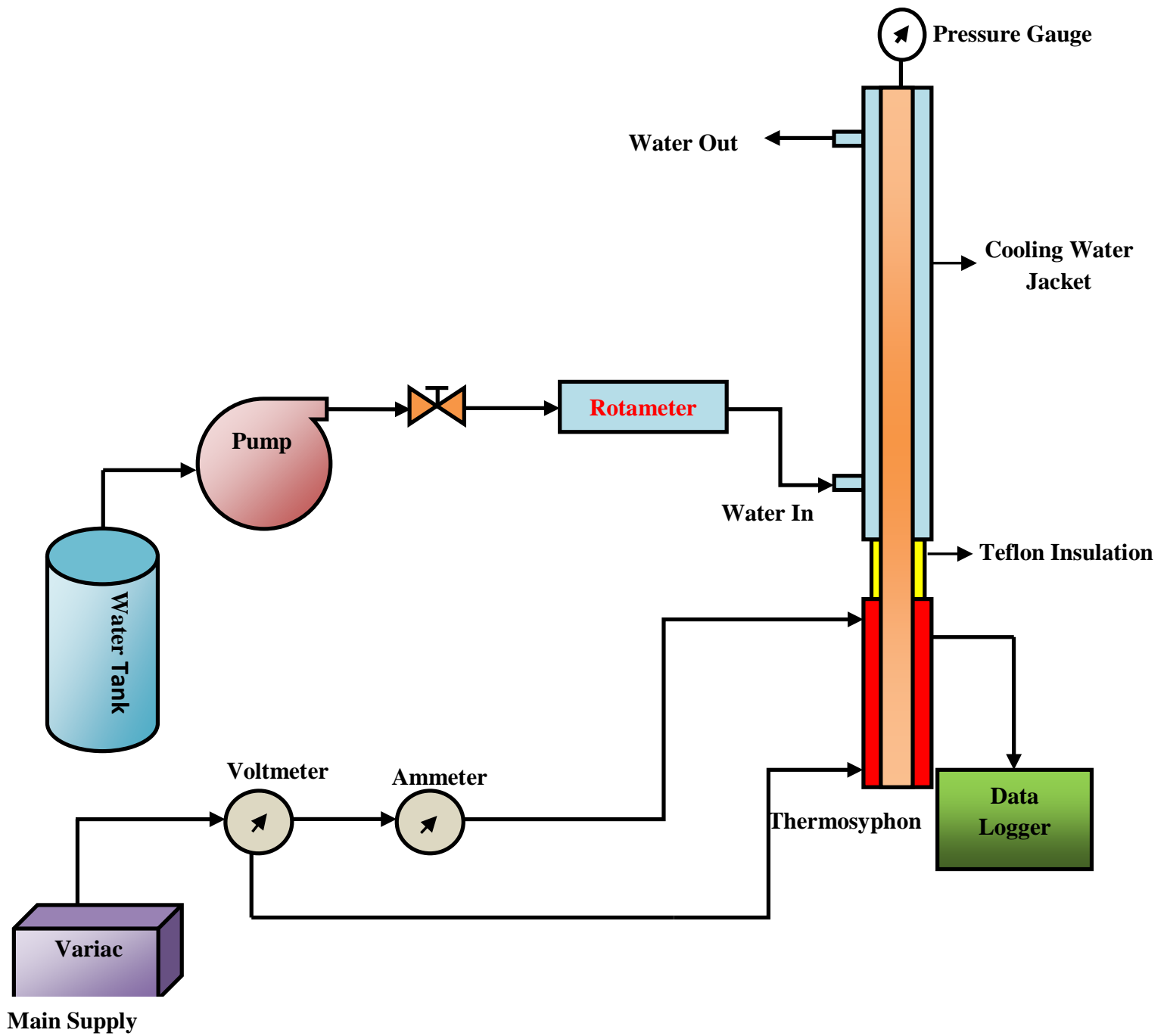

Fig. 2 Schematic diagram of the experimental set-up

\section{DATA ANALYSIS}

The efficiency of TPGAT is expressed as the ratio of output heat from the condenser to input heat provided at the evaporator as given by Eqn. (1).

$$
\eta=\frac{Q_{\text {out }}}{Q_{\text {in }}}
$$

The amount of heat transfer to the thermosyphon is calculated from the formula given below:

$$
Q_{\text {in }}=V I-Q_{\text {loss }}
$$

where Qloss is the total heat loss from the evaporator section by radiation and free convection as shown in Eqs. 2 to 4.

$$
\begin{aligned}
& Q_{\text {loss }}=Q_{\text {rad }}+Q_{\text {conv }} \\
& Q_{\text {rad }}=\varepsilon \sigma A\left(T_{\text {ins }}^{4}-T_{\text {surr }}^{4}\right) \\
& Q_{\text {conv }}=h_{\text {conv }} A\left(T_{\text {ins }}-T_{\text {surr }}\right)
\end{aligned}
$$

The heat transfer co- efficient is evaluated using the eqn. (6) given by Churchchill et al. (1975:

$$
N u=\frac{\mathrm{h}_{\text {conv }} \mathrm{L}_{\mathrm{t}}}{\mathrm{k}_{\mathrm{surr}}}=\left\{0.825+\frac{0.387 R a^{1 / 6}}{\left[1+\left(\frac{0.492}{P r}\right)^{9 / 16}\right]^{8 / 27}}\right\}^{2}
$$

where

$$
R a=\frac{g \beta\left(T_{\text {ins }}-T_{\text {surr }}\right) L_{t}^{3}}{\alpha \vartheta}
$$

The quantity of heat transferred to the coolant water is calculated from the temperature difference of the water at inlet and outlet, taking into account the water mass flow rate and specific heat as shown in Eqn. (7).

$$
Q_{\text {out }}=m c_{p}\left(T_{\text {out }}-T_{\text {in }}\right)
$$

The thermocouples used have a precision of $0.1^{\circ} \mathrm{C}$. The maximum precision of ammeter and voltmeter are $1 \mathrm{~V}$ and $0.1 \mathrm{~A}$. 


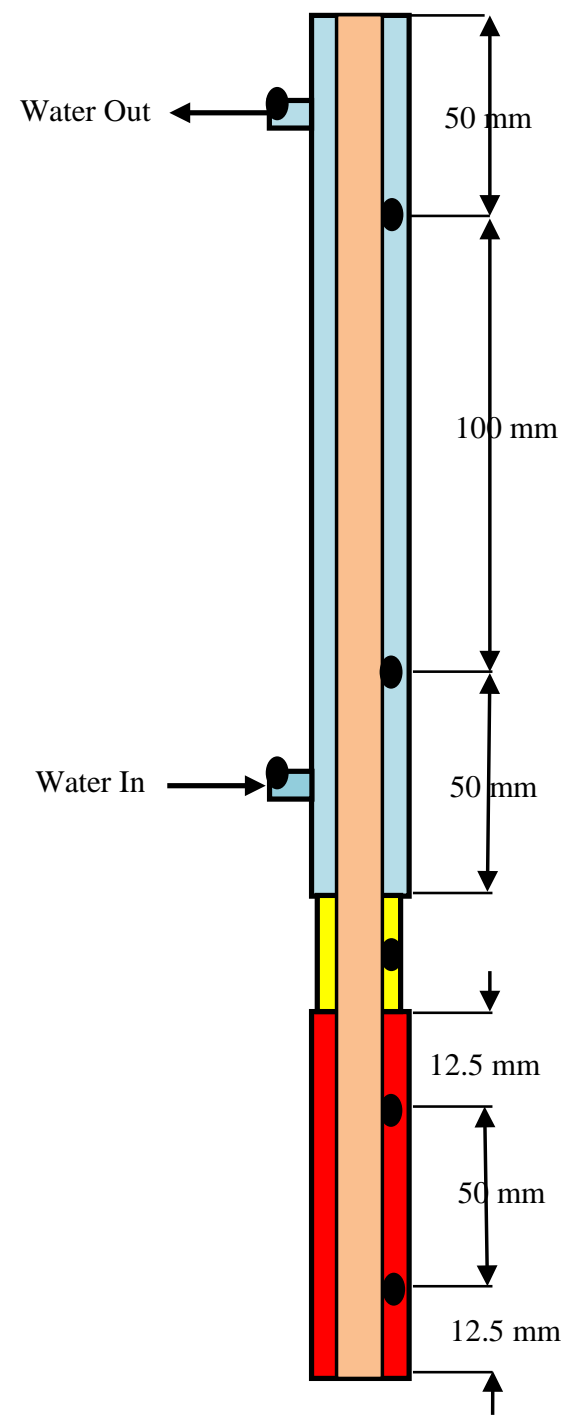

NOT TO SCALE

Fig. 3 Locations of Thermocouples on TPGAT

\section{RESULTS AND DISCUSSION}

The performance of the TPGAT is analysed for various nanofluids of different concentration by varying the heat inputs and fill ratios. The temperature distribution along the length of the TPGAT and the efficiency evaluated are used as the parameter to compare the performance.

\subsection{Temperature distribution along the length of the TPGAT}

Figure 4 shows the temperature variation along the length of the TPGAT for various heat inputs of $115 \mathrm{~W}, 160 \mathrm{~W}, 200 \mathrm{~W}$ and $230 \mathrm{~W}$ for pure water and various nanofluids as heat transfer fluid at $100 \%$ fill ratio. In the case of $\mathrm{Al}_{2} \mathrm{O}_{3}$ /water nanofluid the results were shown for three concentrations of $0.5 \%, 1 \%$ and $2 \%$ and in the case of $\mathrm{ABCNCP} /$ water and $\mathrm{VBCNCP} /$ water the results were shown for the two concentrations of $0.5 \%$ and $1 \%$. It is seen from the figure, that there is an observable decrease in temperature in the evaporator section for all the nanofluids when compared with water as the heat transfer fluid. In the case of $\mathrm{Al}_{2} \mathrm{O}_{3}$ /water nanofluid, the decrease in temperature of the evaporator section is in direct proportion to the increase in the nanoparticle concentration. However in the case of $\mathrm{CNCP} /$ water, the $0.5 \%$ concentration has only a marginal decrease in evaporator temperature whereas a considerable decrease in temperature is observed when the nanoparticle concentration is $1 \%$. Further among the two CNCPs, VBCNCP is reducing the temperature higher than $\mathrm{ABCNCP}$ at all heat input conditions and concentrations.

The decrease in temperature shows that the presence of nanoparticle increases the evaporation rate. Higher concentration of nanoparticles intensifies the mechanisms responsible for enhanced heat transfer. Usually, the major thermal resistance is caused by the formation of large vapor bubbles at the liquid solid interface. In the case of nanofluid as the working fluid, the suspended nanoparticles tend to bombard the vapor bubbles during the bubble formation (Noie et al. 2009). Therefore, the nucleation size of vapor bubble is much smaller for fluid with suspended nanoparticles than that without them. Further the increase in thermal conductivity, Brownian motion, dispersion and fluctuation of nanoparticles especially near the wall leads to increase in the energy transfer rates and increase the heat transfer rate between the fluid and the evaporator section wall.

It is also seen from the figure that the temperature of the nanofluid is lower along the length of the adiabatic and condensor section when compared to water as the working fluid. This shows that for a given heat input, the operating temperature of the TPGAT is lower when nanofluid is used as the heat transfer fluid. Hence it is possible to operate the same TPGAT under higher heat flux conditions when nanofluid is employed as the heat transfer fluid.

Figures 5 and 6 show the temperature variation along the TPGAT for various heat inputs and for different nanofluids with fill ratios of $75 \%$ and $50 \%$ respectively. The trend is similar to the case of $100 \%$ fill ratio. Further on comparing the Fig. 4 with the Figs. 5 and 6 it is clearly seen that the decrease in fill ratio increases the evaporator temperature. This is due to the reduction in contact surface between the heat transfer fluid and the heat transfer surface where the heat transfer coefficient is high.

\subsection{Efficiency of TPGAT}

Figure 7 shows the efficiency of TPGAT at various heat inputs for pure water and all nanofluids of various concentration at $100 \%$ fill ratio. It is seen from the figure that efficiency of the TPGAT increases as the heat input increases. This is due to the minimum inertial thermal resistance and the heat loss associated in the heat exchange process are same at all heat inputs. Hence the efficiency is low at lower heat input. Further it is seen that there is an increase in efficiency with the increase in concentration of the nanofluid. However this increase is $33 \%$ at the lower heat input of $115 \mathrm{~W}$ and $13 \%$ at the higher heat input of $230 \mathrm{~W}$ when the concentration of $\mathrm{Al}_{2} \mathrm{O}_{3}$ nanoparticle in the nanofluid increases from $0 \%$ to $2 \%$. Similarly in the case of VBCNCP, the efficiency increases by $25 \%$ and $12.5 \%$ respectively for the heat inputs of $115 \mathrm{~W}$ and $230 \mathrm{~W}$, when the concentration of nanoparticle increases from $0 \%$ to $1 \%$. In the case of ABCNCP the increase in efficiency is $26 \%$ and $9.96 \%$ respectively for the heat inputs of $115 \mathrm{~W}$ and $230 \mathrm{~W}$, when the concentration of nanoparticle increases from $0 \%$ to $1 \%$. The higher increase in efficiency of TPGAT with nanofluids shows that effect of nanoparticles play a major role in bombarding the vapour bubbles.

Figures 8 and 9 show the above said similar variation for the case of $75 \%$ fill ratio and $50 \%$ fill ratio respectively. It is seen from the figures that in case of pure water the efficiency is $62.2 \%$ and $64.5 \%$ respectively for fill ratios of $75 \%$ and $50 \%$ when the heat input is $115 \mathrm{~W}$. The efficiency of the above said two cases are much higher compared to $50.1 \%$ for the case of $100 \%$ fill ratio as seen in Fig. 7. As there is a considerable effect on the performance of the TPGAT with fill ratio, a separate study is made to analyse the effect of fill ratio. 


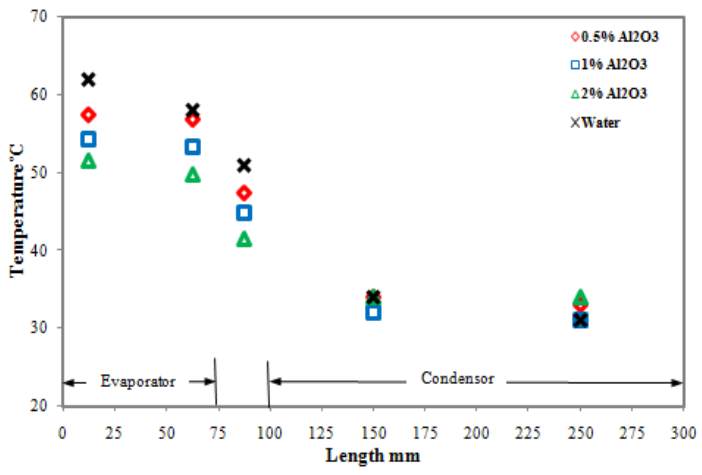

(a) $Q_{\text {in }}=115 \mathrm{~W}, \mathrm{Al}_{2} \mathrm{O}_{3} /$ Water

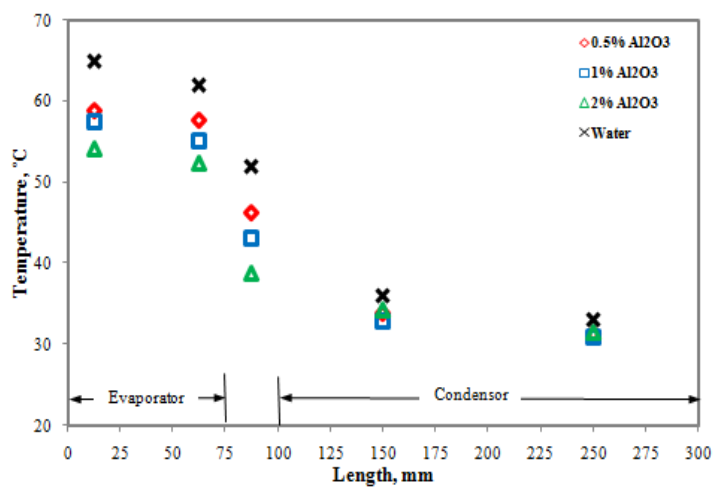

(c) $\mathrm{Q}_{\text {in }}=160 \mathrm{~W}, \mathrm{Al}_{2} \mathrm{O}_{3} /$ Water

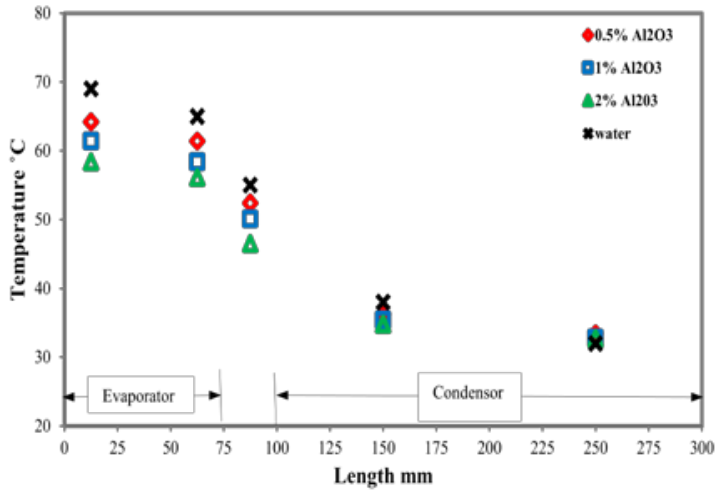

(e) $Q_{\text {in }}=200 \mathrm{~W}, \mathrm{Al}_{2} \mathrm{O}_{3} / \mathrm{Water}$

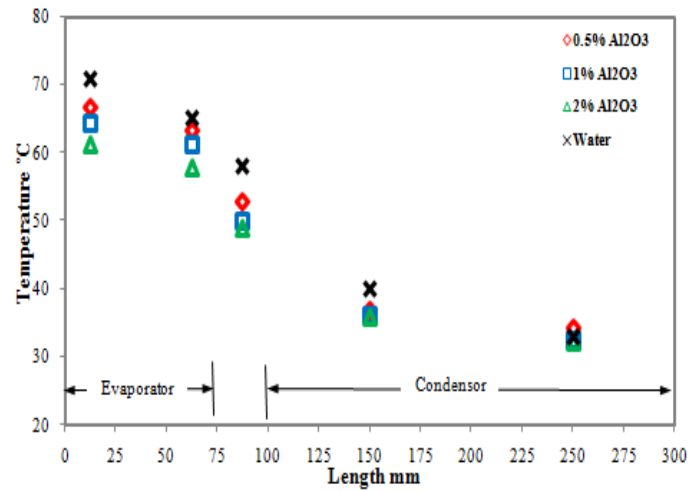

(g) $Q_{\text {in }}=230 \mathrm{~W}, \mathrm{Al}_{2} \mathrm{O}_{3} /$ Water

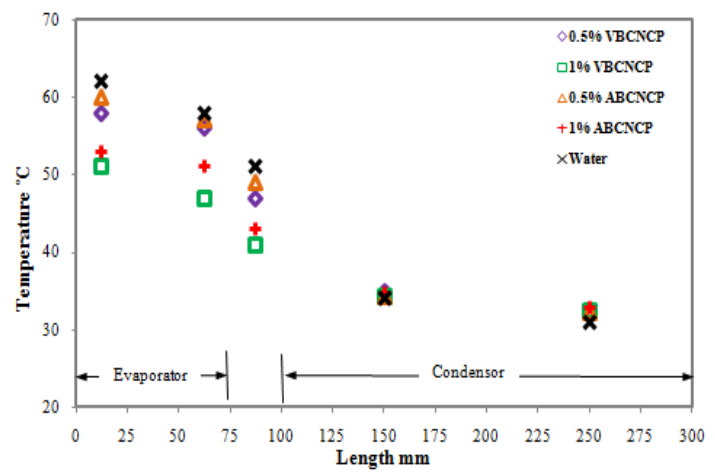

(b) $Q_{\text {in }}=115 \mathrm{~W}, \mathrm{CNCP} /$ Water

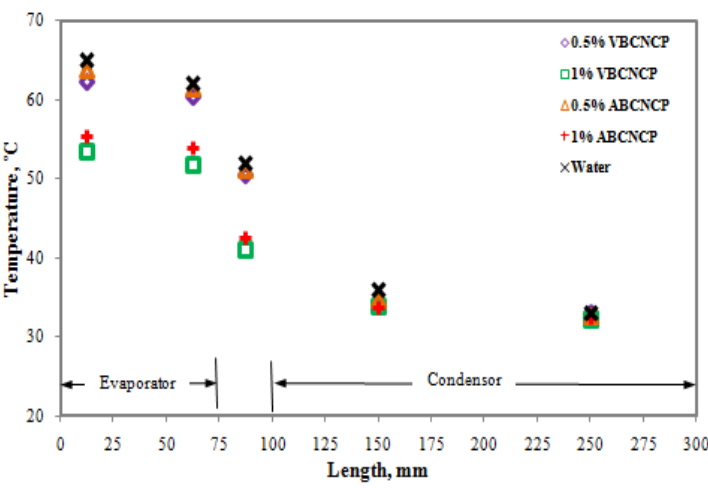

(d) $Q_{\text {in }}=160 \mathrm{~W}$, CNCP/Water

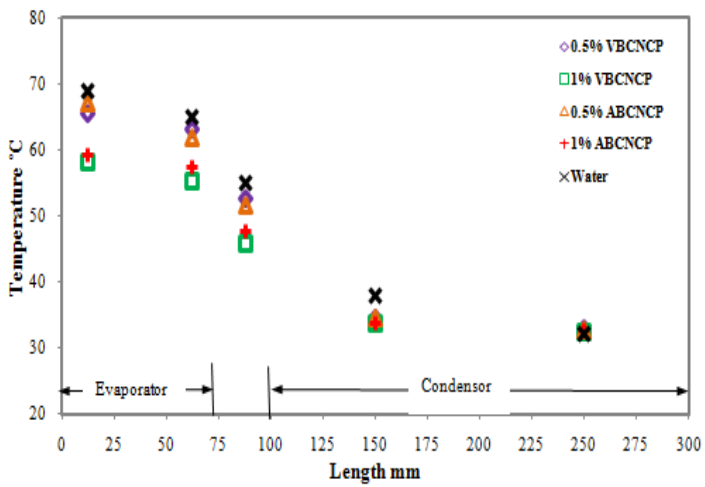

(f) $Q_{\text {in }}=200 \mathrm{~W}, \mathrm{CNCP} / \mathrm{Water}$

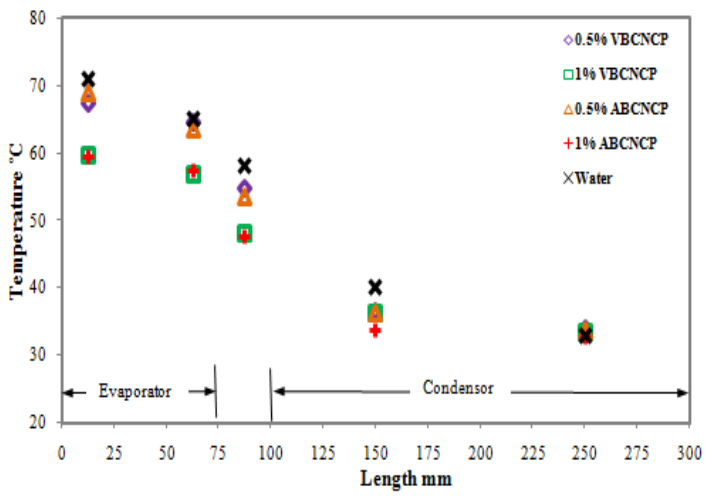

(h) $Q_{\text {in }}=230 \mathrm{~W}, \mathrm{CNCP} / \mathrm{Water}$

Fig. 4 Temperature Distribution of TPGAT for various heat inputs and various concentrations of nanoparticles at $100 \%$ fill ratios 


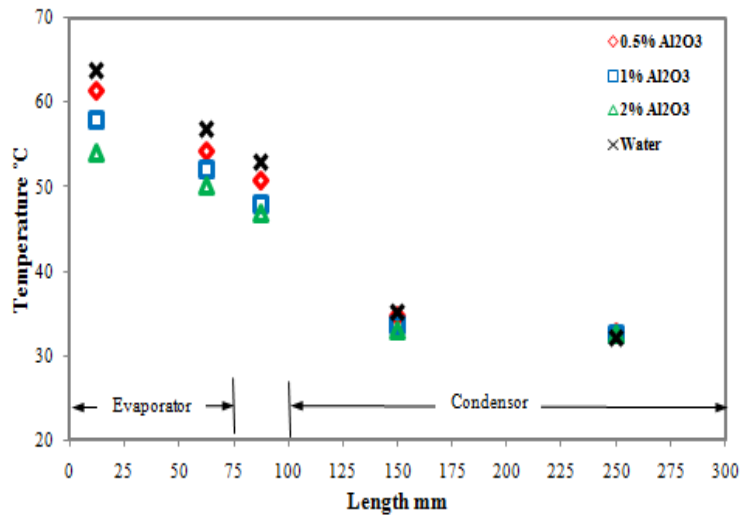

(a) $Q_{\text {in }}=115 \mathrm{~W}, \mathrm{Al}_{2} \mathrm{O}_{3} /$ Water

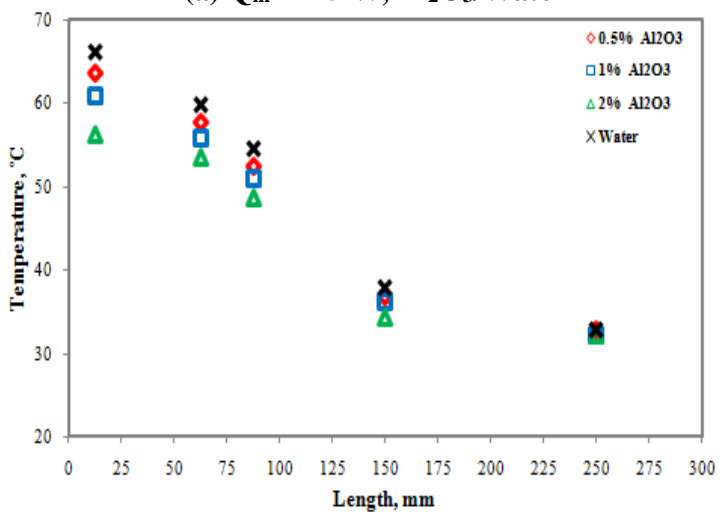

(c) $Q_{\text {in }}=160 \mathrm{~W}, \mathrm{Al}_{2} \mathrm{O}_{3} /$ Water

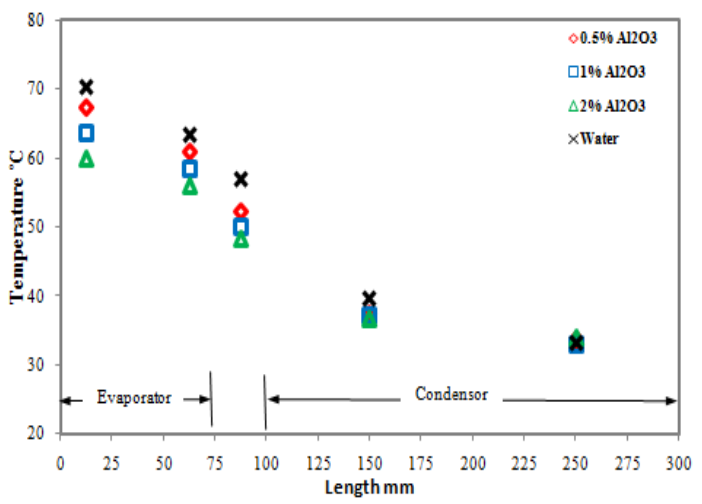

(e) $Q_{\text {in }}=200 \mathrm{~W}, \mathrm{Al}_{2} \mathrm{O}_{3} /$ Water

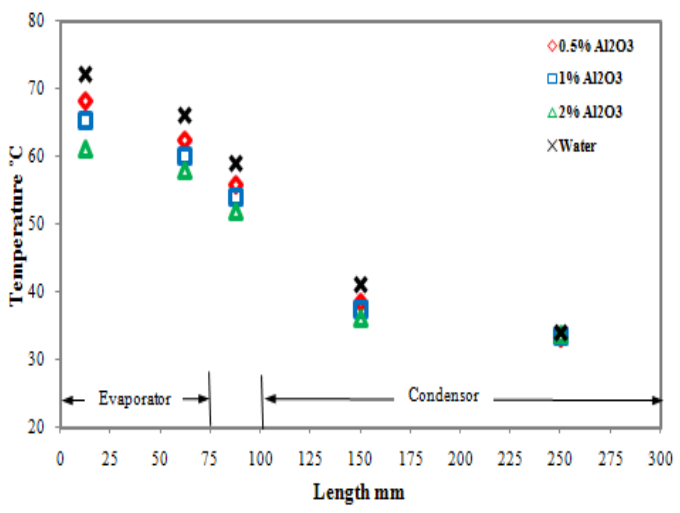

(g) $\mathrm{Q}_{\text {in }}=230 \mathrm{~W}, \mathrm{Al}_{2} \mathrm{O}_{3} /$ Water

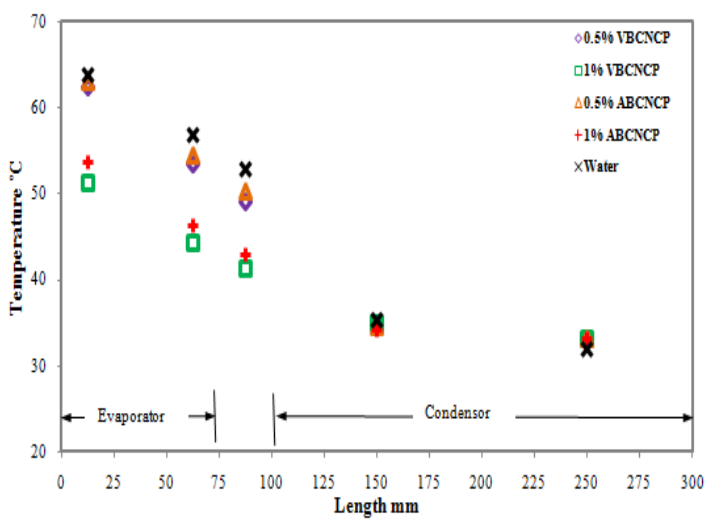

(b) $Q_{\text {in }}=115$ W, CNCP/Water

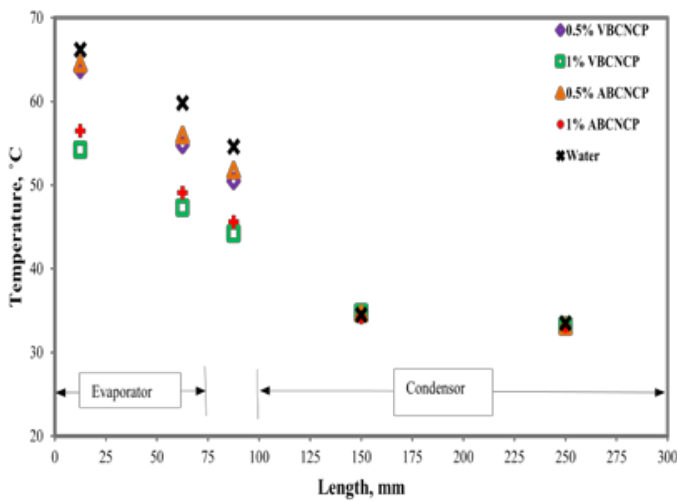

(d) $Q_{\text {in }}=160 \mathrm{~W}, \mathrm{CNCP} / \mathrm{Water}$

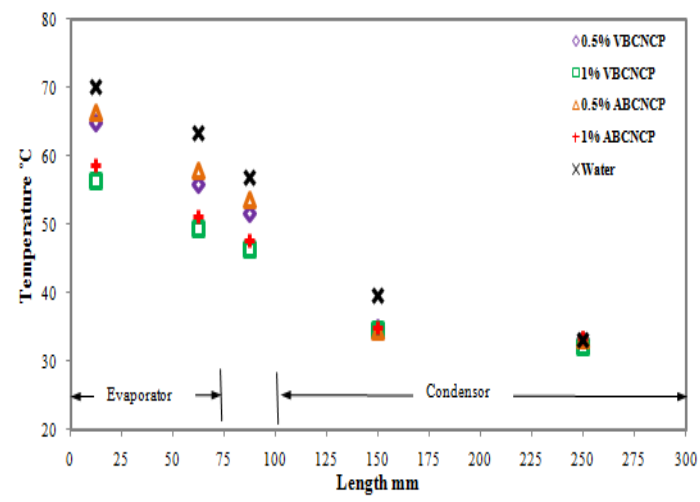

(f) $Q_{\text {in }}=200 \mathrm{~W}, \mathrm{CNCP} /$ Water

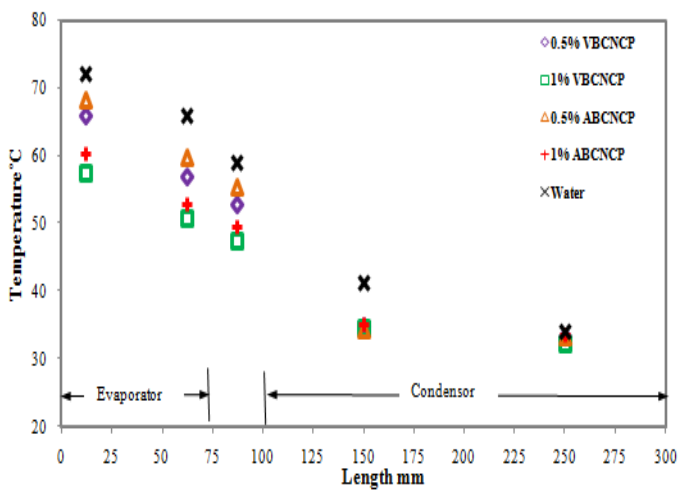

(h) $Q_{\text {in }}=230 \mathrm{~W}$, CNCP/Water

Fig. 5 Temperature Distribution of TPGAT for various heat inputs and various concentrations of nanoparticles at $75 \%$ fill ratios 


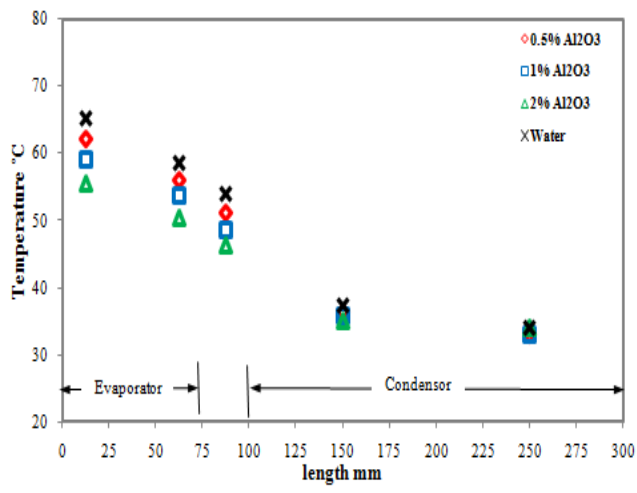

(a) $\mathrm{Q}_{\text {in }}=115 \mathrm{~W}, \mathrm{Al}_{2} \mathrm{O}_{3} /$ Water

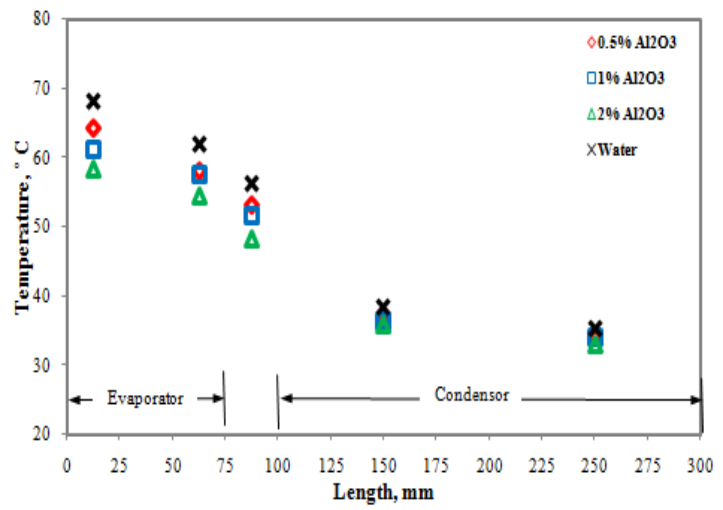

(c) $Q_{\text {in }}=160 \mathrm{~W}, \mathrm{Al}_{2} \mathrm{O}_{3} /$ Water

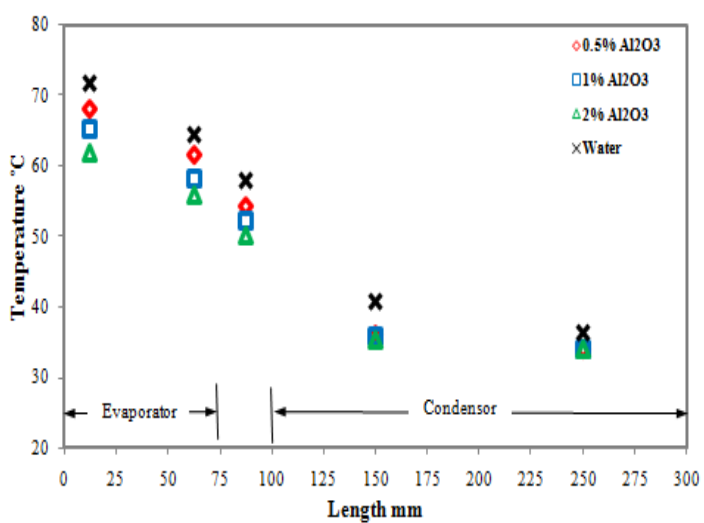

(e) $Q_{\text {in }}=200 \mathrm{~W}, \mathrm{Al}_{2} \mathrm{O}_{3} /$ Water

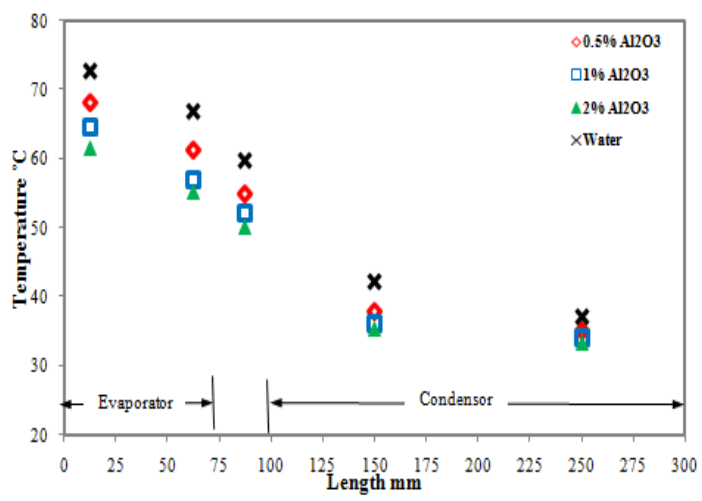

(g) $Q_{\text {in }}=230 \mathrm{~W}, \mathrm{Al}_{2} \mathrm{O}_{3} /$ Water

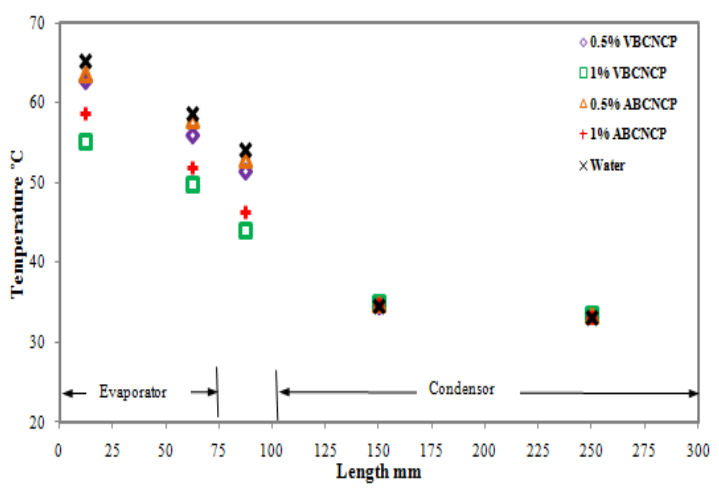

(b) $Q_{\text {in }}=115 \mathrm{~W}, \mathrm{CNCP} /$ Water

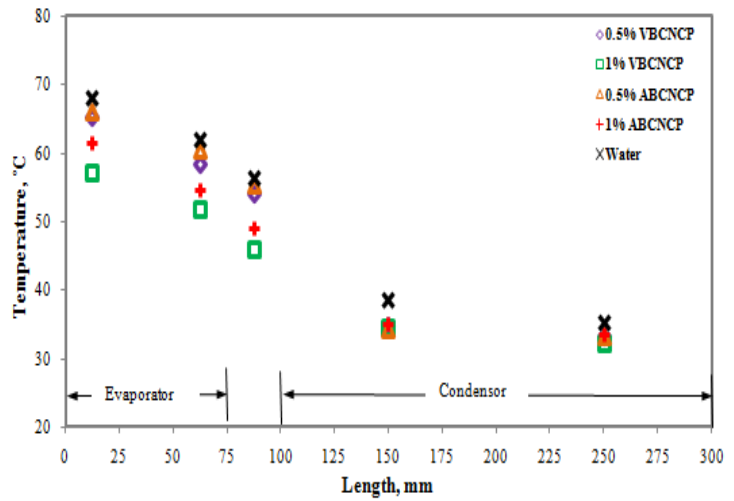

(d) $Q_{\text {in }}=160 \mathrm{~W}$, CNCP/Water

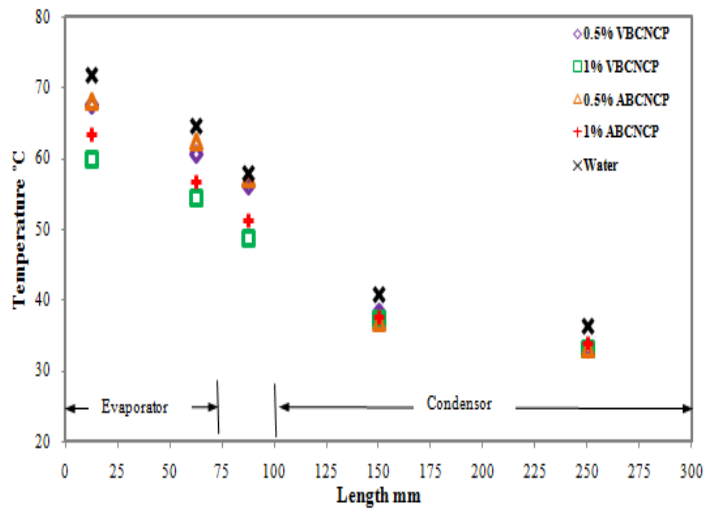

(f) $Q_{\text {in }}=200 \mathrm{~W}, \mathrm{CNCP} / \mathrm{Water}$

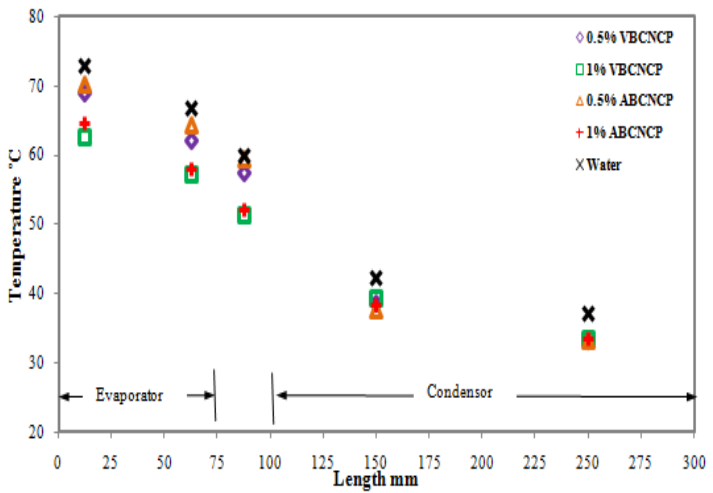

(h) $Q_{\text {in }}=230 \mathrm{~W}$, CNCP/Water

Fig. 6 Temperature Distribution of TPGAT for various heat inputs and various concentrations of nanoparticles at $50 \%$ fill ratios 


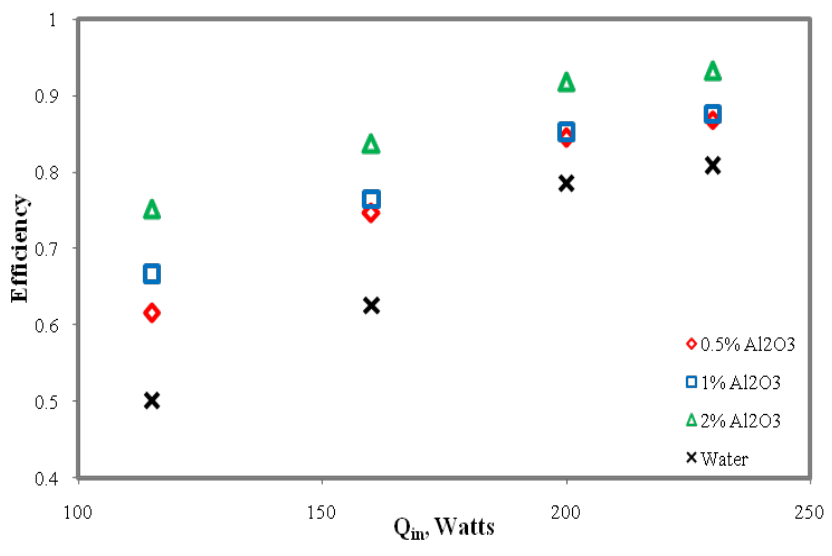

(a) $\mathrm{Al}_{2} \mathrm{O}_{3} /$ Water

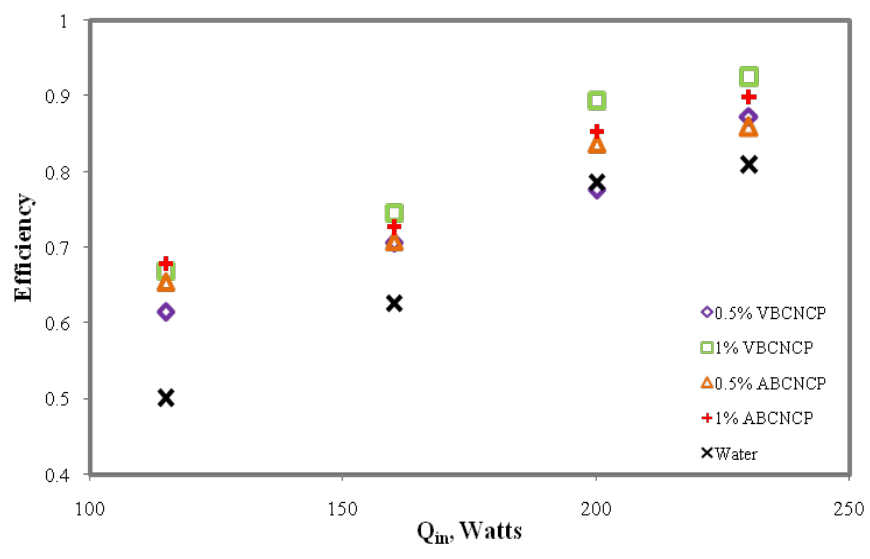

(b) CNCP/Water

Fig. 7 Efficiency Vs Qin for various concentrations of nanoparticles at $100 \%$ fill ratio

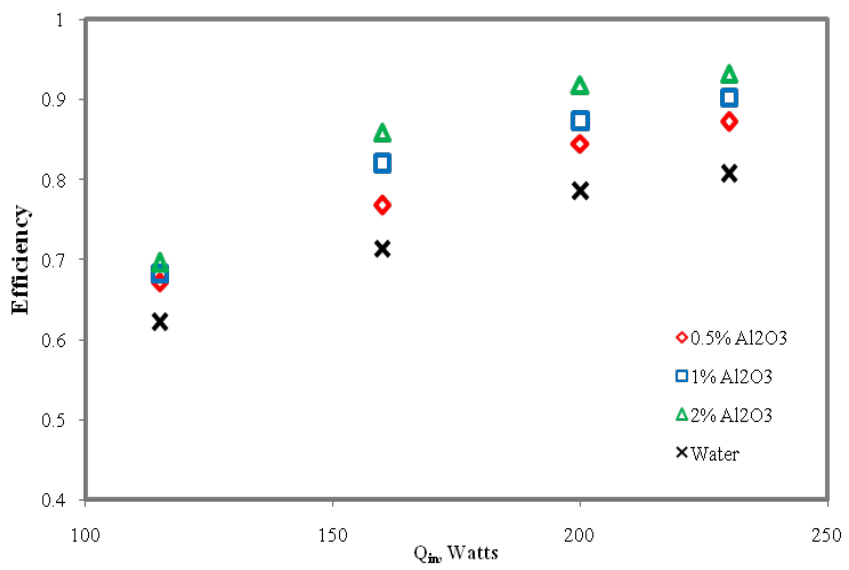

(a) $\mathrm{Al}_{2} \mathrm{O}_{3} /$ Water

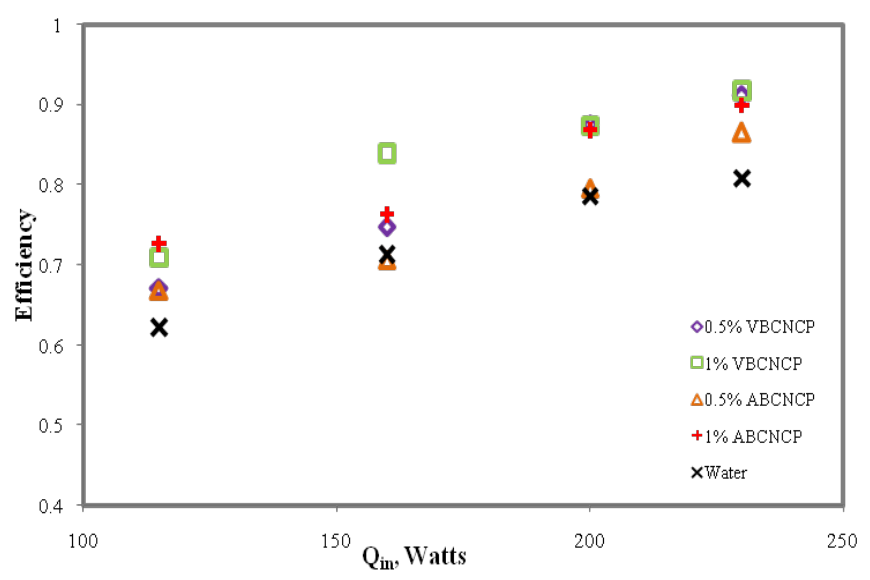

(b) CNCP/Water

Fig. 8 Efficiency Vs $Q_{\text {in }}$ for various concentrations of nanoparticles at $75 \%$ fill ratio

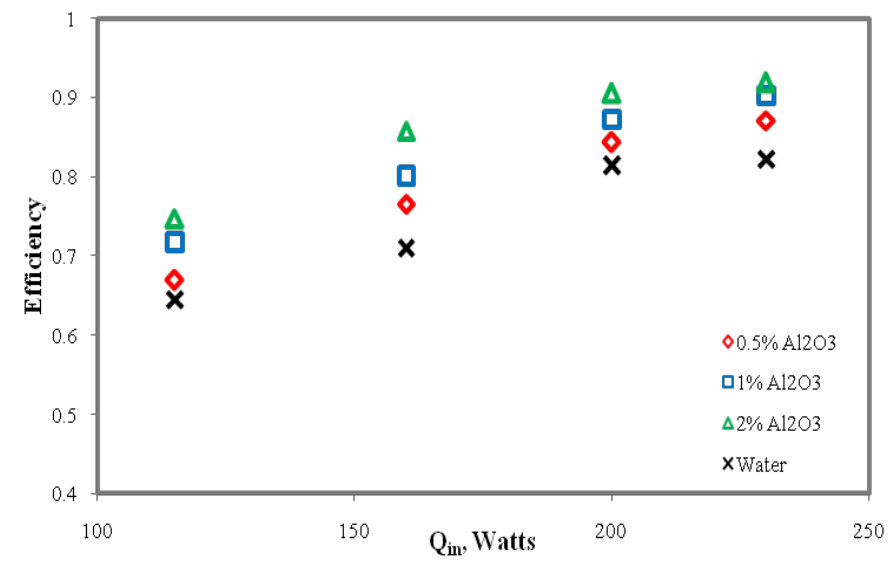

(a) $\mathrm{Al}_{2} \mathrm{O}_{3}$ /Water

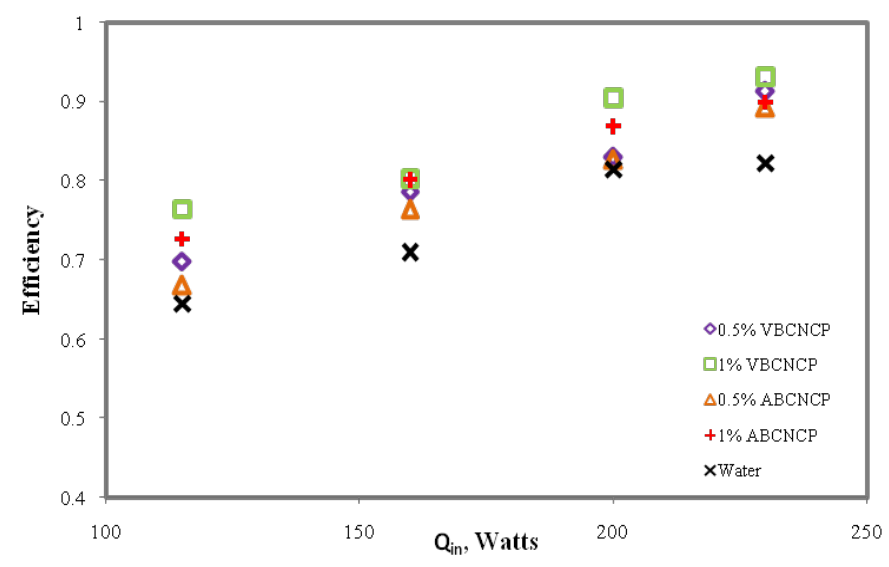

(b) CNCP/Water

Fig. 9 Efficiency Vs Qin for various concentrations of nanoparticles at $50 \%$ fill ratio 


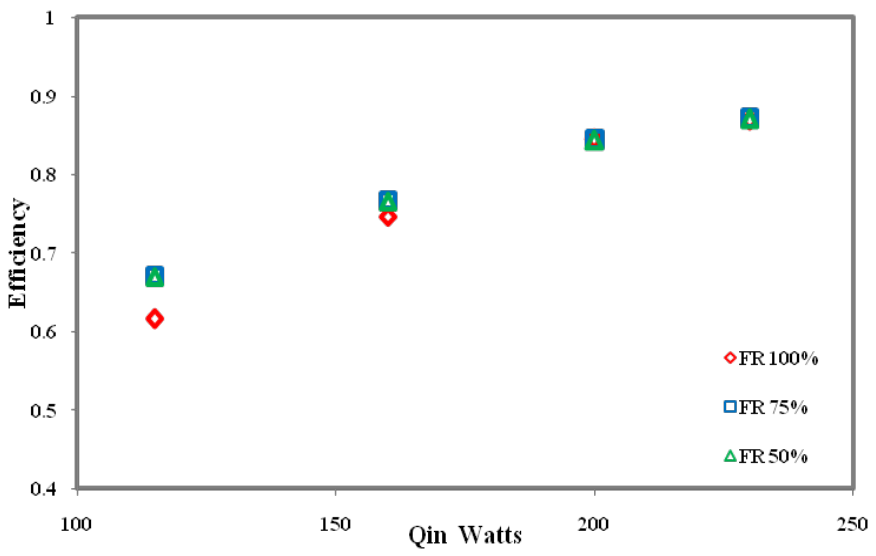

(a) $0.5 \% \mathrm{Al}_{2} \mathrm{O}_{3}$

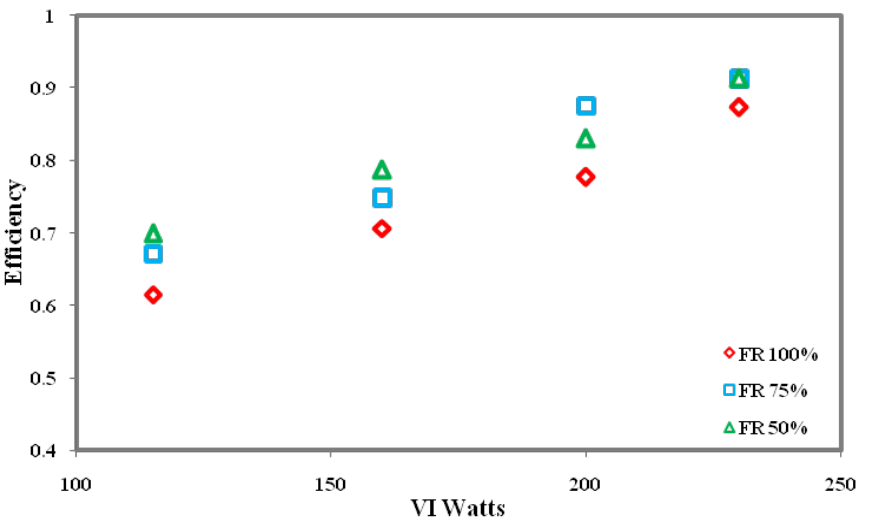

(b) $0.5 \% \mathrm{VBCNCP} /$ Water

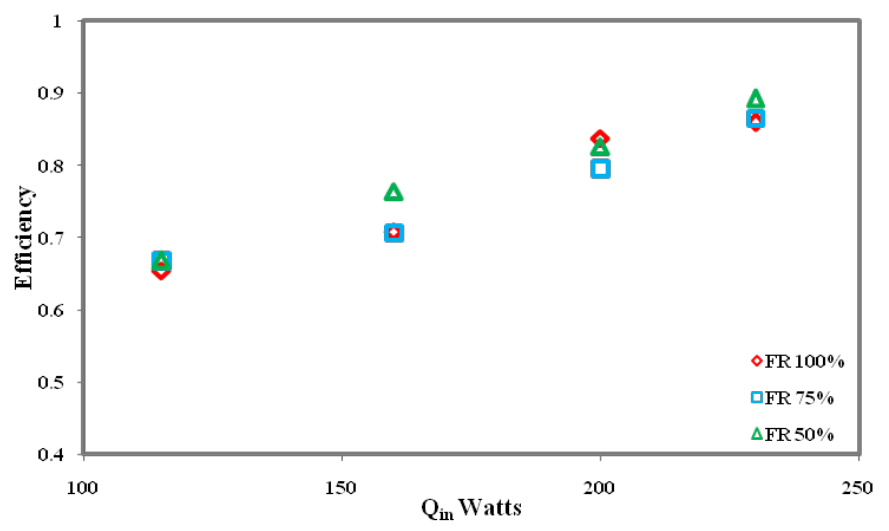

(c) $0.5 \% \mathrm{ABCNCP} /$ Water

Fig. 9 Effect of fill ratios on the efficiency of TPGAT with concentration of $0.5 \%$ nanoparticles

\subsection{Effect of fill ratio}

Figures 9 and 10 show the efficiency of TPGAT for the various heat inputs at different fill ratios of $50 \%, 75 \%$ and $100 \%$ for nanoparticles concentrations of $0.5 \%$ and $1 \%$ nanoparticles respectively. The lower efficiency in the case of higher fill ratio shows that the rate of condensation is lower when the fill ratio is higher. This could be due to the heat transfer mechanism in the condensor section that changes from film condensation to a two phase mixture convection which causes the decrease of thermosyphon performance. However at higher heat flux, there is no difference in efficiency with respect to fill ratio. This is due to the higher heat flux which decreases the fluid level in the evaporator section which reduces the evaporator performance particularly at lower fill ratio. Hence the advantage received in the condensor section at lower fill ratio is compensated by the reduction in performance in the evaporator section due to more dry out at lower fill ratio.

\section{CONCLUSION}

This paper aims at improving the efficiency of TPGAT using $\mathrm{Al}_{2} \mathrm{O}_{3}$ /water , $\mathrm{VBCNCP}$ /water, VBCNCP /water as the working fluids with different concentration.

- For all nanofluids the temperature distributions along the TPGAT were at lower level for the nanofluids than for the pure water as the suspended nanoparticles tend to bombard the vapour bubbles during evaporation process. Hence it is possible to operate the same TPGAT under higher heat flux conditions when the nanofluids is employed as the heat transfer fluid.

- The increase in concentration of the nanoparticle in the nanofluid increases the efficiency of TPGAT in all the cases of nanofluids and this effect is more predominant at lower heat input.

- The decrease in fill ratio increases the evaporator temperature due to reduction in contact surface between the working fluid and heat transfer surface where heat transfer coefficient is high.

- The lower efficiency in the case of higher fill ratio shows that the rate of condensation is lower when the fill ratio is higher. This could be due to the heat transfer mechanism in the condensor section that changes from film condensation to a two phase mixture convection which causes the decrease of thermosyphon performance. However at higher heat flux, there is no difference in efficiency with respect to fill ratio. This is due to the higher heat flux which decreases the fluid level in the evaporator section which reduces the evaporator performance particularly at lower fill ratio. Hence the advantage received in the condensor section at lower fill ratio is compensated by the reduction in performance in the evaporator section due to more dry out at lower fill ratio. 


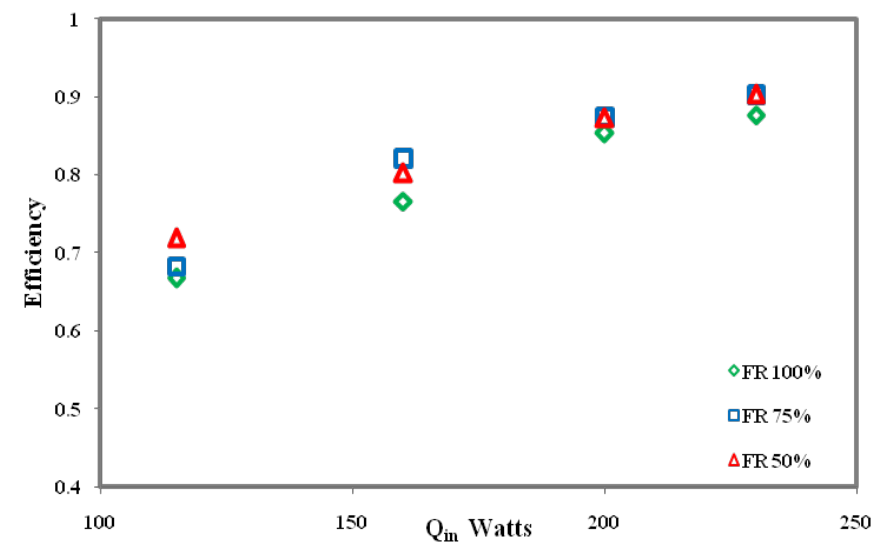

(a) $1 \% \mathrm{Al}_{2} \mathrm{O}_{3}$

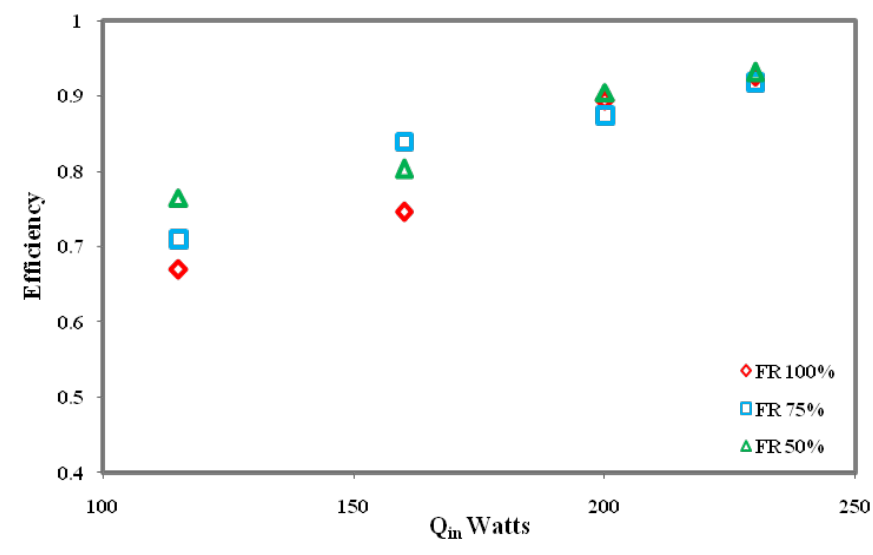

(b) $1 \%$ VBCNCP/Water

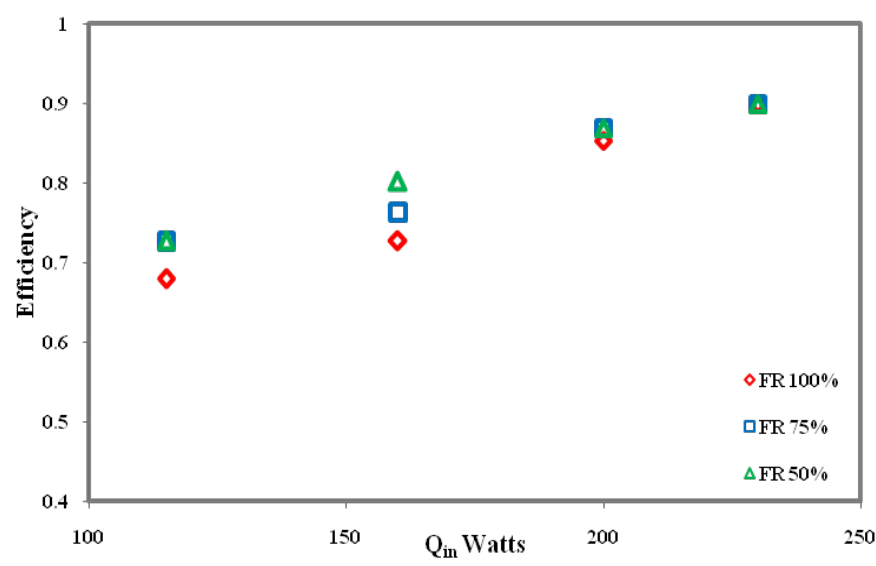

(c) $1 \%$ ABCNCP/Water

Fig. 10 Effect of fill ratios on the efficiency of TPGAT with concentration of $1 \%$ nanoparticles

\section{ACKNOWLEDGEMENTS}

We are very thankful to Dr. R.V.Seeniraj, Dean, Department of Mechanical Engineering, Rajalakshmi Engineering College, for his technical support during the conduct of experiments and Dr. P.S. Venkatnarayanan, for providing the samples of VBCNCP and ABCNCP.

\section{NOMENCLATURE}

A surface area of insulated tube $\left(\mathrm{m}^{2}\right)$

$\mathrm{C}_{\mathrm{p}} \quad$ specific heat of water $(\mathrm{J} / \mathrm{kgK})$

hconv convective heat transfer coefficient $\left(\mathrm{W} / \mathrm{m}^{2 \circ} \mathrm{C}\right)$

I current (A)

ksurr. thermal conductivity of surrounding air $\left(\mathrm{W} / \mathrm{m}^{\circ} \mathrm{C}\right)$

$\mathrm{Lt} \quad$ total length of tube (m)

m coolant water mass flow rate $(\mathrm{kg} / \mathrm{s})$

$\mathrm{Nu} \quad$ Nusselt number

Pr Prandtl number

Qconv heat transfer by convection (W)

Q $\quad$ rate of heat entering at the evaporator section (W)

Qout rate of heat released at the condensor section (W)

Qrad radiation heat transfer rate (W)
Ra Rayleigh number

$\mathrm{T}_{\text {in }} \quad$ inlet temperature of cooling water (K)

Tins $\quad$ temperature on external surface of insulation (K)

Tout outlet temperature of cooling water (K)

$\mathrm{T}_{\text {surr }} \quad$ surrounding temperature $(\mathrm{K})$

V voltage (V)

Greek letters

$\alpha \quad$ thermal diffusivity $\left(\mathrm{m}^{2} / \mathrm{s}\right)$

$\varepsilon \quad$ emissivity factor of insulation

$\sigma \quad$ Boltzmann constant $\left(\mathrm{W} / \mathrm{m}^{2} \mathrm{~K}^{4}\right)$

$\eta \quad$ efficiency of TPGAT

$\vartheta \quad$ momentum diffusivity $\left(\mathrm{m}^{2} / \mathrm{s}\right)$

\section{REFERENCES}

Maxwell .J.C, 1873, A Treative on Electricity and Magnetism, Dover publications.

Bang, I. C., and Chang, S.H., 2005, "Boiling Heat Transfer Performance and Phenomena of $\mathrm{Al}_{2} \mathrm{O}_{3}$ Water Nanofluids from a Plain Surface in a Pool," International Journal of Heat and Mass Transfer, 48, 2407-2419. 


\section{http://dx.doi.org/10.1016/j.ijheatmasstransfer.2004.12.047}

Choi, S.U.S.,1995, "Development and Applications of NonNewtonian Flows," 66 (Ed. D. A. Singiner and H.P. Wang), ASME, $99-106$.

Choi, S.U.S., and Eastman, J.A., 1995, "Enhancing Thermal Conductivity of Fluids with Nanoparticles, "International Mechanical Engineering Congress and Exhibition, san Francisco,CA.

Churchill, Stuart, W., and Humbert, HS Chu, 1975, "Correlating Equations for Laminar and Turbulent Free Convection from a Vertical Plate," International Journal of Heat and Mass Transfer, 18(11), 1323-1329.

http://dx.doi.org/10.1016/0017-9310(75)90243-4

Huminic, G., Huminic, A., Morjan, I., and Dumitrache, F., 2001, "Experimental Study of the Thermal Performance of Thermosyphon Heat Pipe using Iron Oxide Nanoparticles," International Journal of Heat and Mass Transfer, 54(1), 656-661.

Kang, S.W, Wei, W. C., Tsai, S. C. and Yang. S.Y., 2006,"Experimental Investigation of Silver Nano Fluid on Heat Pipe Thermal Performance," Applied Thermal Engineering, 26, 2377 2382.

http://dx.doi.org/10.1016/j.applthermaleng.2006.02.020

Liu, Z. H., Yang, X. F., Wang, G. S., \& Guo, G. L., 2010, “Influence of Carbon Nanotube Suspension on the Thermal Performance of a Miniature Thermosyphon”, International Journal of Heat and Mass Transfer, 53(9), 1914-1920.

http://dx.doi.org/10.1016/j.ijheatmass transfer.2009.12.065

Manimaran, R., Palaniradja, K., \& Alagumurthi, N., 2012,"Effect of Filling Ratio on Thermal Characteristics of Circular Heat Pipe Using Nanofluid," Frontiers in Heat Pipes (FHP), 3(2).

http://dx.doi.org/10.5098/fhp.v3.2.3004

Moffat, Robert J., 1975, "Using Uncertainty Analysis in the Planning of an Experiment." ASME, Transactions, Journal of Fluids Engineering (ISSN 0098-2202) 107, 173-178.

Naphon, Paisarn, Dithapong Thongkum., and Pichai Assadamongkol., 2009, "Heat Pipe Efficiency Enhancement with Refrigerant-Nanoparticles Mixtures." Energy Conversion and Management, 50(3), 772-776. http://dx.doi.org/10.1016/j.enconman.2008.09.045

Noie, S. H., Heris, S. Z., Kahani, M., and Nowee, S. M., 2009, “Heat Transfer Enhancement using $\mathrm{Al}_{2} \mathrm{O}_{3}$ /water Nanofluid in a Two-Phase Closed Thermosyphon, "International Journal of Heat and Fluid Flow, 30(4), 700-705.

http://dx.doi.org/10.2298/TSCI110201003S

Paramatthanuwat, T., Boothaisong, S., Rittidech, S., and Booddachan, K., 2010, "Heat Transfer Characteristics of a TwoPhase Closed Thermosyphon using De Ionized Water Mixed with Silver Nano”, Heat and Mass Transfer, 46(3), 281-285.

http://dx.doi.org/10.1007/s00231-009-0565-y

Park, Yong Joo, Hwan Kook Kang, and Chul Ju Kim., 2002, "Heat Transfer Characteristics of a Two-Phase Closed Thermosyphon to the Fill Charge Ratio." International Journal of Heat and Mass Transfer, 45(23), 4655-4661. http://dx.doi.org/10.1016/S0017-9310(02)00169-2

Shanthi, R., ANANDAN, S. S., and Ramalingam, V., 2012, "Heat Transfer Enhancement Using Nanofluids," Thermal Science, 16(2), 423-444.

http://dx.doi.org/10.2298/TSCI110201003S

Venkatanarayanan. P.S., Velmurugan, R., and Joseph Stanley, A., 2011, "Experimental Characterisation of Catalyst-Free Carbon Nanomaterials from Mixed Vegetable and Animal Base Oils through Modified Traditional Process,” Journal of Nanomaterials, vol. 2011, Article ID 959818, 10 pages.

Wang, Q.X., and Mujumdar, S. A., 2007,"Heat Transfer Characteristics of Nanofluids: a Review, "International Journal of Thermal Sciences, 46(1), 1-19.

http://dx.doi.org/10.1016/j.ijthermalsci.2006.06.010.

Wasekar, V. M., and Manglik, R. M., 2000, "Pool Boiling Heat Transfer in Aqueous Solutions of an Anionic Surfactant", Journal of Heat Transfer, 122(4), 708-715.

http://dx.doi.org/10.1115/1.1316785

Wei .S.W., Tsai, S. H., Yang, S.,Y. and Kang, S.W., 2005, "Effect of Nano Fluid Concentration on Heat Pipe Thermal Performance," IASME Trans, 2, 1432-1439. 